\title{
Cryotherapy: biochemical alterations involved in reduction of damage induced by exhaustive exercise
}

\author{
A.B.V. Furtado ${ }^{1}$, D.D. Hartmann ${ }^{2}$, R.P. Martins ${ }^{2}$, P.C. Rosa ${ }^{2}$, I.K. da Silva ${ }^{2}$, B.S.L. Duarte ${ }^{1}$ \\ L.U. Signori ${ }^{1}$, F.A.A. Soares ${ }^{2}$ and G.O. Puntel ${ }^{1,2,3}$
}

${ }^{1}$ Centro de Ciências da Saúde, Programa de Pós-graduação em Reabilitação Funcional, Universidade Federal de Santa Maria, Santa Maria, RS, Brasil

${ }^{2}$ Centro de Ciências Naturais e Exatas, Programa de Pós-Graduação em Ciências Biológicas, Bioquímica Toxicológica, Universidade Federal de Santa Maria, Santa Maria, RS, Brasil

${ }^{3}$ Centro de Ciências da Saúde, Departamento de Morfologia, Universidade Federal de Santa Maria, Santa Maria, RS, Brasil

\begin{abstract}
When exercises are done in intense or exhaustive modes, several acute biochemical mechanisms are triggered. The use of cryotherapy as cold-water immersion is largely used to accelerate the process of muscular recovery based on its anti-inflammatory and analgesic properties. The present study aimed to study the biochemical effects of cold-water immersion treatment in mice submitted to exercise-induced exhaustion. Swiss albino mice were divided into 4 treatment groups: control, cold-water immersion (CWI), swimming exhaustive protocol (SEP), and SEP + CWI. Treatment groups were subdivided into times of analysis: $0,1,3$, and 5 days. Exhaustion groups were submitted to one SEP session, and the CWI groups submitted to one immersion session $\left(12 \mathrm{~min}\right.$ at $12^{\circ} \mathrm{C}$ ) every $24 \mathrm{~h}$. Reactive species production, inflammatory, cell viability, and antioxidant status were assessed. The SEP + CWI group showed a decrease in inflammatory damage biomarkers, and reactive species production, and presented increased cell viability compared to the SEP group. Furthermore, CWI increased acetylcholinesterase activity in the first two sessions. The present study showed that CWI was an effective treatment after exercise-induced muscle damage. It enhanced anti-inflammatory response, decreased reactive species production, increased cell viability, and promoted redox balance, which could decrease the time for the recovery process.
\end{abstract}

Key words: Exercise-induced damage; Muscular damage; Reactive species; Cold-water immersion; Therapeutic cold

\section{Introduction}

Chronic adaptations generated by regular physical exercise are well known for their capability to improve health and quality of life. In the long-term perspective, physical exercise causes regulation of metabolism and antioxidant status (1). However, when exercises are done in intense or exhaustive modes, several acute effects are triggered, including excessive inflammation, hormonal changes, and high production of reactive oxygen species, which may lead to oxidative stress, tissue damage, protein oxidation, lipid peroxidation, and DNA damage $(1,2)$. These imbalances in the oxidative process during muscle contraction can contribute to decreases in contractile force, leading to exercise-induced exhaustion and consequently increased susceptibility to muscle damage (3).

It is well known that exercise-induced muscle damage generates an inflammatory response, which is followed by the muscle recovery phase (4). There are numerous methods used by sports medicine that aim to accelerate the muscle recovery process, such as cryotherapy (5).
Although it is frequently used as a recovery method, controversies remain around the real benefits of this treatment. Previous researchers have shown that individuals submitted to cryotherapy have higher levels of antioxidants (6), decrease in oxidative stress (7), and lower levels of inflammation biomarker levels and mitochondrial dysfunction (8). On the other hand, other studies have proven that cryotherapy is not effective in muscle damage or inflammation biomarkers (9), or in decreasing oxidative stress induced by lesions (10).

One of the most popular methods of cryotherapy is cold-water immersion (CWI), which is known for its antiinflammatory and analgesic effects obtained through extreme or moderate exposure of body segments in water below $15^{\circ} \mathrm{C}(11)$. Additionally, recent studies have shown that $\mathrm{CWI}$ is more efficient than other forms of recovery because it causes local vasoconstriction that leads to the reduction of fluid propagation in the interstitial space. Hence, this method favors the reduction of muscle damage,

Correspondence: G.O. Puntel: <gustavopuntel@yahoo.com.br> 
acute inflammation (12), muscle tissue temperature, venous $\mathrm{O}_{2}$ saturation, plasma myoglobin concentration, and swelling (13).

Despite extensive research on CWI, the results are still controversial, which is explained by the diversity of the protocols used in research $(5,11,14,15)$. Such diversity promotes different physiological and biochemical mechanisms triggered by CWI that are not clearly described. In view of this, further studies are important, and then evidence-based guidelines can be developed (6). In a preview study by our group that evaluated the use of cryotherapy in muscle contusion, the use of low temperatures modulated biochemical response (7). Now, we tested a different protocol of muscle lesions induced by exercise and cryotherapy, used here as a continuous treatment with cold-water immersion to test the effect in most of the biochemical markers tested in our first study. Our swimming exhaustive protocol was designed to induce similar biochemical alterations as a skeletal injury model and the biochemical markers were selected taking into account this context. Considering this, the aim of this study was to establish which biochemical changes are induced by $\mathrm{CWI}$ treatment in mice submitted to exercise-induced exhaustion after muscle damage. Our hypothesis was that the CWI protocol would reduce the inflammatory process and reactive species formation, and would increase antioxidant status and cellular viability after exercise-induced muscle damage compared to passive recovery.

\section{Material and Methods}

\section{Animals and reagents}

Adult male Swiss albino mice weighing 30-50 g were used in this study. During the experimental protocol, animals were kept in cages of 10 animals each, with food and water ad libitum. Mice were maintained in a room with controlled temperature and a 12-h light/dark cycle. The room where the experimental procedures occurred had controlled temperature of $22^{\circ} \mathrm{C} \pm 2$. Assay reagents were purchased from Sigma (USA) and biochemical kits were obtained from the standard commercial supplier Labtest (Brazil). All the procedures were in accordance with the guidelines of the Committee on Care and Use of Experimental Animal Resources of the Universidade Federal de Santa Maria, Brazil (UFSM; \#4185290915).

\section{Experimental groups}

The animals $(n=80)$ were randomized and divided into four homogeneous groups: 1) control: animals were not submitted to either protocol of muscle damage (swimming exhaustion protocol, SEP) or treatment (CWI); 2) CWI: animals were submitted only to the CWI protocol;

3) exhaustion: animals were submitted only to SEP;

4) SEP + CWI: animals were submitted to both protocols

All groups were subdivided into four different times of analysis: $0,1,3$, and 5 days. The aim was to observe the evaluation of biomarkers in different periods after exhaustion protocol and single or repeated sessions of CWI treatment. The subgroup sample sizes were calculated by a power analysis based on Puntel et al. (8) and determined that four animals would provide a statistical power of $95 \%$ at an alpha level of $5 \%$.

\section{Water adaptation}

All animals were adapted to the water before the beginning of the experiment. The adaptation consisted of keeping the animals walking in shallow water at $31^{\circ} \mathrm{C}$ for 20 min for 7 days. The aim was to adapt the animals to the water environment without promoting physical training. Warm water was used because, as shown in our results, cold-water immersion could promote biochemical changes at the first contact.

\section{Swimming exhaustion protocol}

The SEP and SEP + CWI groups were submitted to the SEP according to the method proposed by Huang (16) with some modifications. It consisted of a swimming exercise in a tank with controlled temperature $\left(31^{\circ} \mathrm{C}\right)$ carrying constant loads of $10 \%$ of the body weight (17) that were fixed on mice tails. Exhaustion was characterized by the animal losing the coordinated movements and not returning to the surface within $7 \mathrm{~s}$. The animals were submitted to the exercise only once on day 0 .

\section{Cold-water immersion}

After the exhaustion protocol, the animals of SEP + $\mathrm{CWI}$ were immediately put in a tank with controlled temperature $\left(12^{\circ} \mathrm{C}\right)$ for 12 min following the protocol previously described by Machado et al. (15). The water depth was controlled so that the animal had the whole body submerged (except the head) without needing to swim to stay on the surface, that is, with the four paws resting on the floor of the tank. The animals of the CWI group were submitted to the same protocol. Both groups repeated the protocol every $24 \mathrm{~h}$ for 5 days (Figure 1 ). To minimize significant variations in the time scale of the endogenous temperature, after the cold-water immersion the animals were dried with towels and then re-allocated in the cages. This procedure was done at room temperature in order not to interfere with the physiological response to immersion.

\section{Tissue sampling}

The animals were euthanized and blood was collected by heart puncture in previously heparinized syringe. Both gastrocnemius muscles were quickly removed, weighed, and placed on ice. Skeletal muscle tissue samples were homogenized within $10 \mathrm{~min}$ in 10 volumes of cold Tris $10 \mathrm{mM}(\mathrm{pH} 7.4)$ and centrifuged at $4000 \mathrm{~g}$ for $10 \mathrm{~min}$ at $4^{\circ} \mathrm{C}$ to yield the low-speed supernatant fraction (S1) that was used for different biochemical assays in all trials. Whole blood samples were centrifuged at $1500 \mathrm{~g}$ for $10 \mathrm{~min}$ at $4^{\circ} \mathrm{C}$ for plasma separation for biochemical analyses. 


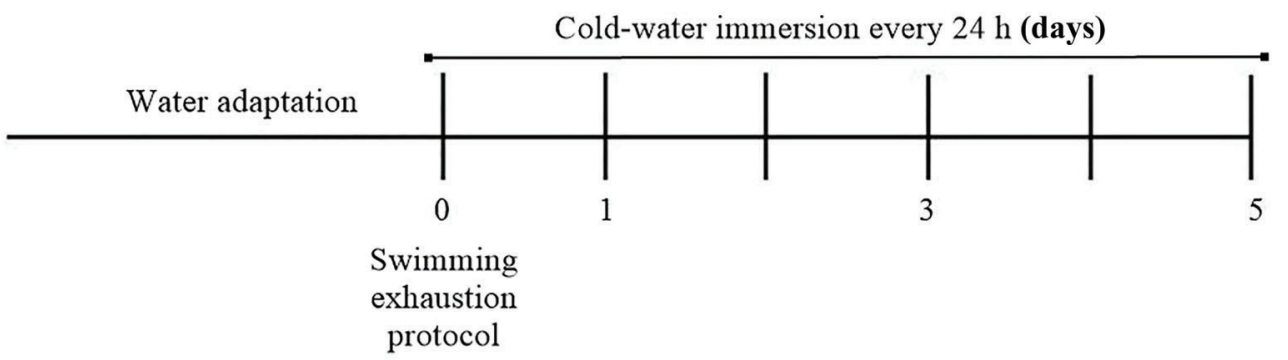

Figure 1. Timeline of the experiments.

\section{Damage markers in skeletal muscle and plasma}

Oxidized dichlorofluoresceine reactive species (DCF$R S)$ levels. DCF-RS levels were measured according to Perez-Severiano (19) with some modifications. Aliquots of skeletal muscle homogenate $(50 \mu \mathrm{L})$ were added to a medium containing Tris- $\mathrm{HCl}$ buffer $(10 \mathrm{mM} ; \mathrm{pH} 7.4)$ and dichloro-dihydro-fluorescein diacetate $(1 \mu \mathrm{M})$. The medium was then incubated in the dark for $1 \mathrm{~h}$ until fluorescence measurement (excitation at 488nm and emission at $525 \mathrm{~nm}$; both slit widths used were at $1.5 \mathrm{~nm}$ ). DCF-RS levels were determined using a standard curve of DCF and the results were corrected by $\mathrm{mg}$ of protein.

Acetylcholinesterase (AChE) activity. AChE activity was estimated in skeletal muscle by the Ellman method (21) using a plate containing acetylcholine iodide (ATC) used as substrate and etopropazine as butyrylcholinesterase (BChE) inhibitor. Data were corrected by protein content and are reported in $\mu \mathrm{mol}$ of ATC hydrolyzed $\cdot \mathrm{min}^{-1} \cdot \mathrm{mL}^{-1}$.

Creatine kinase (CK). CK activity was measured spectrophotometrically in plasma samples by standard biological kits (Labtest, Brazil).

\section{Cell viability and antioxidant markers in skeletal muscle}

Measurement of methyltetrazolium (MTT) reduction levels. Aliquots of skeletal muscle homogenate $(90 \mu \mathrm{L})$ were added to a medium containing $1 \mathrm{mg} / \mathrm{mL}$ of MTT and were incubated in the dark for $60 \mathrm{~min}$ at $37^{\circ} \mathrm{C}$. Then, $900 \mu \mathrm{L}$ of DMSO was added. Formazan levels were measured spectrophotometrically at $570 \mathrm{~nm}$ and $630 \mathrm{~nm}$ and results were corrected by the protein content as proposed by Mosmann (18).

Non-protein thiol (-SH) levels. Non-protein -SH levels were determined according to the method proposed by Ellman (20) with some modifications. Samples of skeletal muscle homogenate $(500 \mu \mathrm{L})$ were precipitated with $5 \%$ trichloroacetic acid $(250 \mu \mathrm{L})$ and subsequently centrifuged at $1800 \mathrm{~g}$ for $10 \mathrm{~min}$ at $4^{\circ} \mathrm{C}$.

The supernatant fraction $(300 \mu \mathrm{L})$ was then added to a reaction medium containing TFK $(0.5 \mathrm{mM}, \mathrm{pH} 7)$ and DTNB (20 mM). Non-protein -SH levels were measured spectrophotometrically at $412 \mathrm{~nm}$. Results were calculated in relation to a standard curve constructed with $\mathrm{GSH}$ at known concentrations and corrected by the protein content.

\section{Protein quantification}

The protein content was estimated by the Bradford method (22) using bovine serum albumin (BSA) as the standard.

\section{Statistical analysis}

Graphpad Prism 6 (USA) was used for all analyses. Data are reported as means $\pm S D$ and variations between interventions are reported as mean differences (MD) and $95 \%$ confidence intervals $(95 \% \mathrm{Cl})$. Significance was assessed by two-way analysis of variance (ANOVA) followed by Tukey's post hoc test. Statistical significance was set at $P<0.05$. The main effects (effect size) were tested to reveal the size of the effect and complement $P$ value (21) and are presented only when interactions between SEP and SEP + CWI were significant.

\section{Results}

\section{Time to exhaustion}

The mean swimming time of the exhaustive protocol was $343.3 \mathrm{~s}( \pm 121.1)$.

\section{Damage markers in skeletal muscle and plasma}

DCF-RS levels in skeletal muscle tissue are reported in Figure 2. SEP significantly increased DCF-RS levels immediately after the exercise $(P<0.05)$ compared to control (MD -1.51 $\eta \mathrm{mol} \mathrm{DCF} / \mathrm{mg}$ protein, $95 \% \mathrm{Cl}-2.446$ to -0.58 ), CWI (MD1.20 $\eta \mathrm{mol} \mathrm{DCF} / \mathrm{mg}$ protein, 95\% Cl 2.13 to 0.27 ), and SEP + CWI (MD $1.31 \mathrm{\eta mol} \mathrm{DCF} / \mathrm{mg}$ protein, $95 \% \mathrm{Cl}$ 0.38 to 2.24 ). For time analysis, there was a difference of the SEP group between day 0 and day 1 (MD $1.49 \eta \mathrm{mol}$ $\mathrm{DCF} / \mathrm{mg}$ protein, $95 \% \mathrm{Cl} 0.53$ to -2.46 ), day 3 (MD $1.12 \mathrm{\eta mol}$ $\mathrm{DCF} / \mathrm{mg}$ protein, $95 \% \mathrm{Cl} 0.1662$ to 2.089 ), and day 5 (MD $1.17 \mathrm{\eta mol} \mathrm{DCF} / \mathrm{mg}$ protein, $95 \% \mathrm{Cl} 0.2091$ to 2.132 ). In effect size (es) analyses, there were differences between SEP and SEP + CWI groups on days 0 (es -1.74) and 5 (es -1.16).

AChE activity in skeletal muscle tissue (Figure 3 ) increased in the CWI group only at day $0(P<0.05)$ 


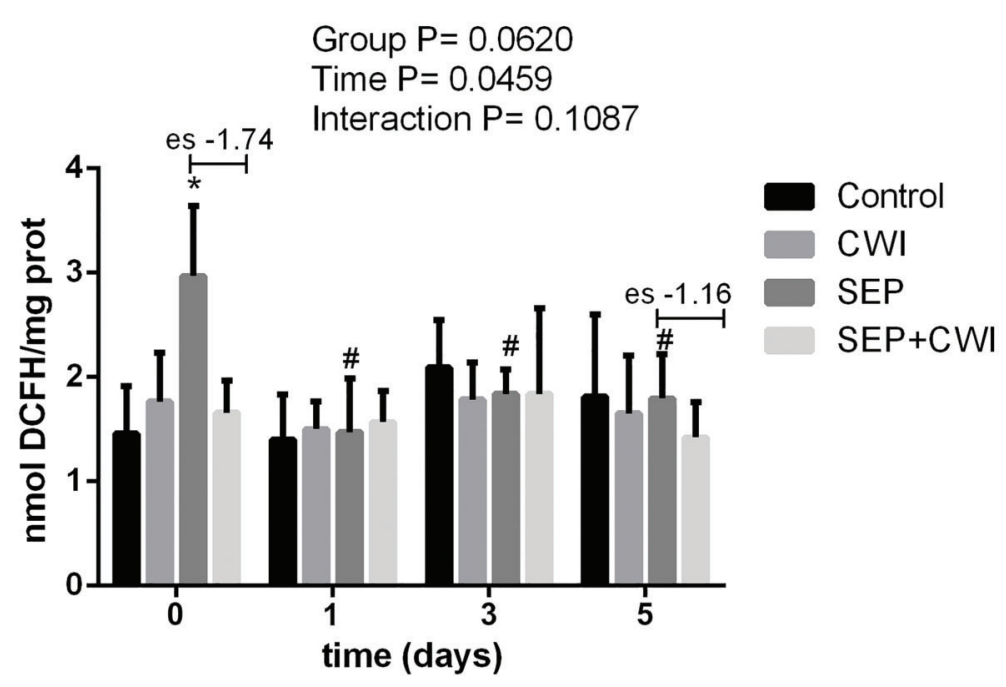

Figure 2. Effects of cold-water immersion (CWI) on dichloro-dihydro-fluorescein diacetate (DCFH) levels. Data are reported as means \pm SD $(n=4)$. ${ }^{*} P<0.05$ for difference between groups at the same time-point; ${ }^{\#} \mathrm{P}<0.05$ for difference between the group at different times (two-way ANOVA, followed by Tukey's post hoc test). es: effect size. SEP: swimming exhaustive protocol.

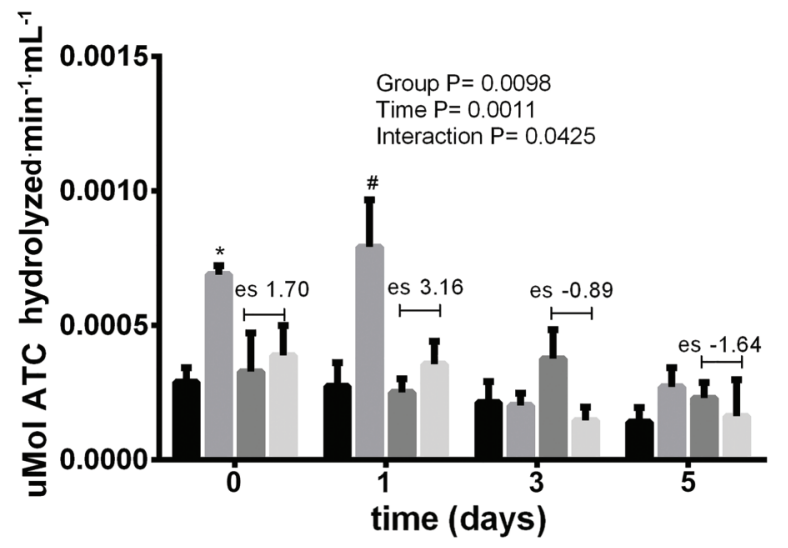

compared to the control group (MD $-0.39 \times 10^{-3} \mu \mathrm{mol}$ ACT hydrolyzed $\cdot \mathrm{min}^{-1} \cdot \mathrm{mL}^{-1}, 95 \% \mathrm{Cl} 0.7480 \times 10^{-3}$ to $-0.05 \times$ $10^{-8} .100^{-5}$ ) and the SEP group (MD $0.361 \times 10^{-3} \mu \mathrm{mol}$ ACT hydrolyzed $\cdot \mathrm{min}^{-1} \cdot \mathrm{mL}^{-1}, 95 \% \mathrm{Cl} 1.25 \times 10^{-8}$ to $\left.0.70 \times 10^{-3}\right)$ and on day $1(\mathrm{P}<0.001)$ compared to all other groups (control, MD $0.0005188 \times 10^{-3} \mu \mathrm{mol}$ ACT hydrolyzed $\cdot \mathrm{min}^{-1} \cdot \mathrm{mL}^{-1}, 95 \% \mathrm{Cl} 0.86$ to 0.17 ; SEP, MD 0.54 , $95 \% \mathrm{Cl} 0.19$ to 0.88 ; SEP $+\mathrm{CWI}$, MD $0.43 \times 10^{-3} \mu \mathrm{mol}$ ACT hydrolyzed $\cdot \mathrm{min}^{-1} \cdot \mathrm{mL}^{-1}, 95 \% \mathrm{Cl} 8.7 \mathrm{e}-005-0.78 \times$ $10^{-3} \mu \mathrm{mol}$ ACT hydrolyzed $\left.\cdot \mathrm{min}^{-1} \cdot \mathrm{mL}^{-1}\right)$. On time analysis, there were differences in CWI between days 0 and 3 (MD 0.0004859, 95\% Cl 0.0001362-0.0008355), 0 and 5 (MD 0.000417, 95\%Cl 6731e-005-0.0007667), 1 and 3 (MD 0.0005891, 95\%Cl 0.0002394-0.0009388), 1 and 5 (MD 0.0005203, 95\%Cl 0.0001706-0.0008699). In effect size analyses, there were differences between SEP and SEP $+\mathrm{CWI}$ groups on all days, however, at immediate time and on day $1, A C h E$ increased in the SEP + CWI group (es $1.70 ; 3.16$ ), and on days 3 and 5 the opposite occurred, AChE was increased in the SEP group (es -0.89; -1.64).
Control

CWI

SEP SEP+CWI

Figure 3. Effects of cold-water immersion (CWI) on acetylcholine iodide (ATC) activity. Data are reported as means $\pm S D(n=4)$. ${ }^{*} P<0.05$ compared to control and swimming exhaustive protocol (SEP); ${ }^{\#} \mathrm{P}<0.05$ compared to all other groups (two-way ANOVA, followed by Tukey's post hoc test). es: effect size
In Figure 4, the positive effect of CWI on CK enzyme modulation can be observed in SEP + CWI. There was a difference between SEP and SEP + CWI groups on days $0(\mathrm{P}<0.05, \mathrm{MD} 34,94 \mathrm{U} / \mathrm{L}, 95 \% \mathrm{Cl} 2.3$ to 67.58$)$, 3 ( $\mathrm{P}<0.001, \mathrm{MD} 42.64 \mathrm{U} / \mathrm{L}, 95 \% \mathrm{Cl} 9.995$ to 75.28$)$, and $5(\mathrm{P}<0.001, \mathrm{MD} 55.68 \mathrm{U} / \mathrm{L}, 95 \% \mathrm{Cl} 23.04$ to 88$)$. These results showed an increase in the CK activity in the SEP group. In effect size analyses, the effects caused by $\mathrm{CWI}$ can be observed on days 0 (es -1.06), 1 (es -1.15), 3 (es -1.97), and 5 (es -1.64).

\section{Cell viability and antioxidant markers in skeletal muscle}

After 5 days of CWI, the MTT levels (Figure 5) presented a significant value on group analysis $(P=0.003$, $F(3,12)=14.31)$ but not on time analyses $(P=0.911)$. Nevertheless, no significant interaction $(P=0.921)$ between the groups was found. In the effect size analyses, MTT levels were increased in the SEP $+\mathrm{CWI}$ group on days 0 and 1 (es $2.90 ; 1.75)$. 
Group $P<0.0001$

Time $P=0.8461$

Interaction $\mathrm{P}=0.6533$

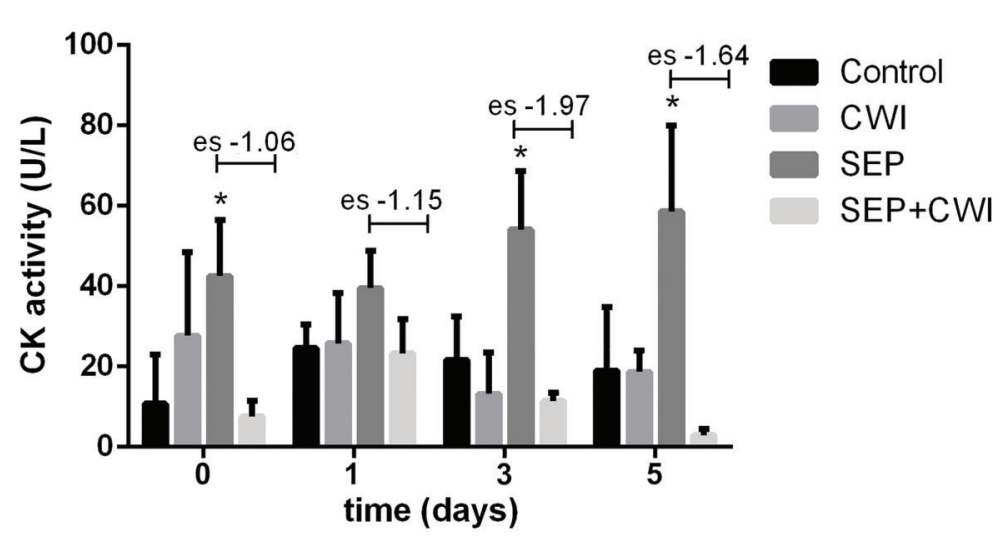

Figure 4. Effects of cold-water immersion (CWI) on creatine kinase $(C K)$ activity. Data are reported as means $\pm S D(n=5) .{ }^{*} P<0.05$ compared to the other groups (two-way ANOVA, followed by Tukey's post hoc test). es: effect size; SEP: swimming exhaustive protocol.
Group $P=0.0003$

Time $P=0.9109$

Interaction $\mathrm{P}=0.9211$

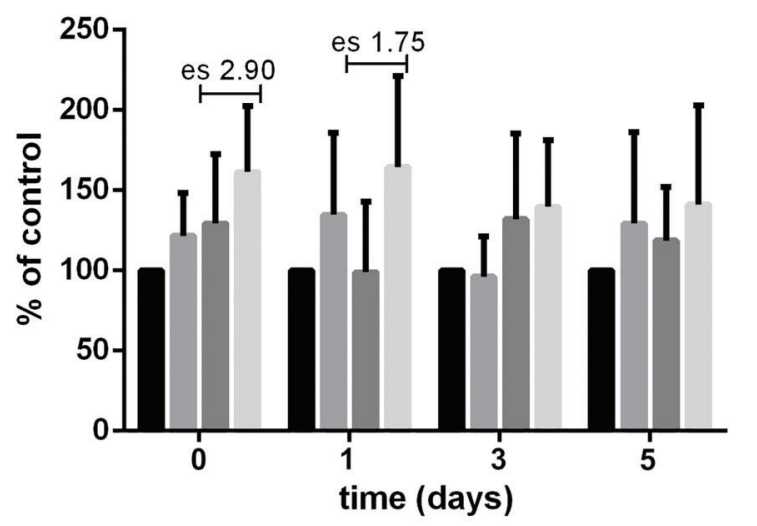

Non-protein -SH levels (Figure 6) presented a significant value on time $(P=0.0446, F(3,36)=2.970)$, but not on group analyses (0.8747) or interaction (0.6307). When Tukey's post hoc test was done, no significant difference was found.

\section{Discussion}

In the current study, biochemical changes induced by $\mathrm{CWI}$ treatment in mice submitted to the SEP protocol were evaluated. Our study is the first to demonstrate an increase in $\mathrm{ACHe}$ activity in the first two sessions of CWI treatment and a decrease afterwards, indicating a modulation of the inflammation system. To the best of our knowledge, this is the first study to demonstrate the use of CWI for five days consecutively after a single exhaustive exercise session, which depicts a significant alteration in muscle recovery.
Figure 5. Effects of cold-water immersion (CWI) on MTT levels. Data are reported as means $\pm S D(n=4)$. $\mathrm{P}>0.05$ (two-way ANOVA, followed by Tukey's post hoc test). es: effect size; SEP: swimming exhaustive protocol.
The most popular reason for using $\mathrm{CWI}$ is that it induces vasoconstriction, which leads to venous return increase, metabolite removal (24), and decreased muscle oxygen saturation (14), restricting the infiltration of inflammatory cells into the muscle (25). These mechanisms protect the uninjured tissue from enzymatic reactions triggered by exercise-induced damage (26). The proposed exhaustive protocol was able to evoke alterations in biochemical markers that clearly indicate muscle damage, such as increased CK activity and DCF-RS production, although the protocol did not lead to excessive damage, which may be equivalent to real sportive situations. Our data demonstrated that CWI treatment after an intense exercise bout was capable of decreasing reactive oxygen species (ROS) formation and damage, as well as increasing cellular viability. The results supported the hypothesis that $\mathrm{CWI}$ is better than passive recovery after exhaustive exercise and 


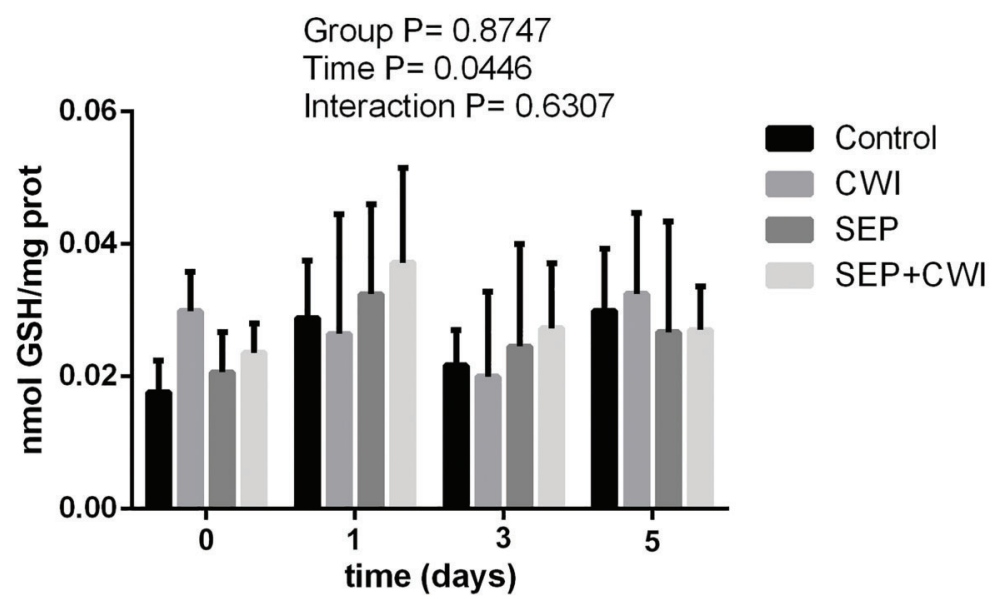

Figure 6. Effects of cold-water immersion (CWI) on non-protein -SH levels. Data are reported as means $\pm S D(n=4)$. $P>0.05$ (two-way ANOVA, followed by Tukey's post hoc test). SEP: swimming exhaustive protocol.

corroborate other studies that suggest that CWI treatment is an effective intervention after exhaustive exercise (5).

There are multiple mechanisms involved in oxidant/ antioxidant status during exercise (27). Excessive levels of ROS may alter the muscle, mainly through inflammatory processes (28). Levels of DCF-RS were increased in the SEP group; however, the SEP + CWI group did not present an increment, which demonstrated that $\mathrm{CWI}$ may prevent the DCF-RS increase caused in our protocol of exerciseinduced exhaustion. This finding clearly demonstrated that $\mathrm{CWI}$ was effective in limiting $\mathrm{RS}$ production just after exercise.

Considering that acetylcholine (ACh) is well known to inhibit tumor necrosis factor- $\alpha$, interleukin- $1 \beta$, and macrophage migration (29), the increased AChE activity may indicate a modulation in ACh levels and in its ability in regulating inflammatory processes (30). In the present study, AChE activity was increased in the CWI group. This unexpected result may be explained by the thermodynamic characteristics of AChE. Klichkhanov and Meilanov (31) reported that when rat erythrocyte membranes are exposed to hypothermia, there is an increase in the degree of substrate inhibition for AChE to the maximum rate and in the Michaelis Menten constant. On the other hand, when exposed to situations of hyperthermia, such as $42-48^{\circ} \mathrm{C}, 60 \%$ of AChE is inactivated (32). Regarding thermodynamics, AChE was increased in CWI, although not in the same magnitude as the exercise situations (SEP and SEP + CWI groups), as a result of exercise-induced hyperthermia. A possible explanation is that cold promoted isometric contractions as an adaption strategy in the first two applications of CWI. After that, the animals were adapted, and therefore, these contractions and AChE activity decreased. Since the increase was observed in the groups that were only submitted to $\mathrm{CWI}$, this finding leads us to believe that exhaustive exercise partially inhibited adaptive effects. Furthermore, regarding only the SEP and SEP + CWI groups, CWI decreased AChE activity $24 \mathrm{~h}$ after damage, which showed that the inflammatory process was likely decreased.
It has already been shown that cryotherapy can weaken or delay the infiltration of inflammatory cells $(8,33)$, which could be explained by vasoconstriction caused by exposure to the cold. This causes the reductionof cellular permeability, and lymphatic and capillary vessels, and consequently reduces fluid propagation into the interstitial space (34). In our study, CK levels increased on all days in the SEP group; however, the same pattern was not observed in the SEP + CWI group. This indicated that SEP was able to cause some degree of muscle damage, which was limited by the CWI protocol used here. Furthermore, the difference between treated and non-treated groups remained for $24-48 \mathrm{~h}$, which is the peak of inflammatory process (35). This result demonstrated that CWI may be an effective intervention after exercise-induced damage even in the most acute phases of inflammation.

Mitochondria plays a key role in energy supply and operates as an indicator of cell viability (36). MTT reduction depends on the oxidoreductase enzyme family activity, such as dehydrogenase enzymes, and it is mainly located in mitochondria (37). In light of this, MTT reduction assay can be used as an indicator of cell viability. In our experiments, CWI improved cell viability through the increase of MTT reduction levels immediately and during the first $24 \mathrm{~h}$. This result proved that $\mathrm{CWI}$ treatment might act by preserving skeletal muscle cell structure and improving cell viability even after exhaustive exercise. Our findings indicated that skeletal muscle cells could have a faster recovery from any damage suffered during exercise once cell viability is preserved by CWI.

In summary, we demonstrated from a biochemical perspective that $\mathrm{CWI}$ is an effective option of treatment after exercise-induced muscle damage. CWI modulated anti-inflammatory response, decreased reactive species production, increased cell viability, and promoted redox balance, which produced an improvement in the recovery process compared to a passive recovery. This reduction in muscle damage promoted by $\mathrm{CWI}$ is relevant and might be used as a basis for future research and in evidence-based 
clinical practice. The comparison of methodologies in future studies is necessary to conclude which are the most effective.

\section{Acknowledgments}

The authors express their gratitude to PPGRF-UFSM and PPGBTOX- UFSM. Financial support was given by CAPES, CNPq, and FAPERGS/CNPq - PRONEM. D.D.

\section{References}

1. McArdle WD, Katch FI, Katch VL. Exercise Physiology: energy, nutrition and human performance. 7 ed. Rio de Janeiro: Guanabara Koogan; 2011.

2. Fittipaldi S, Dimauro I, Mercatelli N, Caporossi D. Role of exercise-induced reactive oxygen species in the modulation of heat shock protein response. Free Radic Res 2014; 48: 52-70, doi: 10.3109/10715762.2013.835047.

3. Ibrahim MY, Ashour OM. Changes in nitric oxide and free radical levels in rat gastrocnemius muscle during contraction and fatigue. Clin Exp Pharmacol Physiol 2011; 38: 791-795, doi: 10.1111/j.1440-1681.2011.05603.x.

4. Smith C, Kruger MJ, Smith RM, Myburgh KH. The inflammatory response to skeletal muscle injury: illuminating complexities. Sports Med 2008; 38: 947-969, doi: 10.2165/ 00007256-200838110-00005.

5. Pournot H, Bieuzen F, Duffield R, Lepretre PM, Cozzolino C, Hausswirth C. Short term eVects of various water immersions on recovery from exhaustive intermittent exercise. Eur J Appl Physiol 2011; 111: 1287-1295, doi: 10.1007/s00421010-1754-6.

6. Bleakley CM, Davison GW. What is the biochemical and physiological rationale for using cold-water immersion in sports recovery? A systematic review. Br J Sports Med 2010; 44: 179-187, doi: 10.1136/bjsm.2009.065565.

7. Mila-Kierzenkowska C, Wozniak A, Wozniak B, Drewa G, Rakowski A, Jurecka A, et al. Whole-body cryostimulation in kayaker women: a study of the effect of cryogenic temperatures on oxidative stress after the exercise. J Sports Med Phys Fitness 2009; 49: 201-207.

8. Puntel GO, Carvalho NR, Amaral GP, Lobato LD, Silveira SO, Daubermann MF, et al. Therapeutic cold: An effective kind to modulate the oxidative damage resulting of a skeletal muscle contusion. Free Radic Res 2011; 45: 125-138, doi: 10.3109/10715762.2010.517252.

9. Rowsell GJ, Coutts AJ, Reaburn P, Hill-Haas S. Effects of cold-water immersion on physical performance between successive matches in high-performance junior male soccer players. J Sports Sci 2009; 27: 565-573, doi: 10.1080/ 02640410802603855.

10. Silva MA, Carvalho TR, Cruz AC, Jesus LR, Silva Neto LA, Trajano ET, et al. Effect of time-dependent cryotherapy on redox balance of quadriceps injuries. Cryobiology 2016; 72: 1-6, doi: 10.1016/j.cryobiol.2016.01.001.

11. Bleakley CM, Bieuzen F, Davison GW, Costello JT. Wholebody cryotherapy: empirical evidence and theoretical perspectives. Open Access J Sports Med 2014; 5: 25-36, doi: $10.2147 /$ OAJSM.S41655.
Hartmann received a fellowship from Coordenação de Aperfeiçoamento de Pessoal de Nível Superior (CAPES/ 132018/2016-0). R.P. Martins received a fellowship from Conselho Nacional de Desenvolvimento Científico e Tecnológico (CNPq/134650/2016-6). I.K. da Silva received a fellowship from Fundação de Amparo à Pesquisa do Estado do Rio Grande do Sul (FAPERGS/05442551/16-0). Additional financial support was provided by FAPERGS/CNPq PRONEM.
12. Degroot DW RP, Thompson SM, Kenefick RW. Extremity cooling for heat stress mitigation in military and occupational settings. J Thermal Biol 2013; 38: 305-310, doi: 10.1016/ j.jtherbio.2013.03.010.

13. Roberts LA, Nosaka K, Coombes JS, Peake JM. Cold water immersion enhances recovery of submaximal muscle function after resistance exercise. Am J Physiol Regul Integr Comp Physiol 2014; 307: R998-R1008, doi: 10.1152/ajpregu. 00180.2014.

14. Hohenauer E, Costello JT, Stoop R, Kung UM, Clarys P, Deliens $\mathrm{T}$, et al. Cold-water or partial-body cryotherapy? Comparison of physiological responses and recovery following muscle damage. Scand J Med Sci Sports 2018; 28: 1252-1262, doi: 10.1111/sms.13014.

15. Machado AF, Ferreira PH, Micheletti JK, de Almeida AC, Lemes ÍR, Vanderlei FM, et al. Can water temperature and immersion time influence the effect of cold water immersion on muscle soreness? A systematic review and meta-analysis. Sports Med 2016; 46: 503-514, doi: 10.1007/s40279-015-0431-7.

16. Huang CC, Hsu MC, Huang WC, Yang HR, Hou CC. Triterpenoid-rich extract from Antrodia camphorata improves physical fatigue and exercise performance in mice. Evid Based Complement Alternat Med 2012; 2012: 364741, doi: 10.1155/2012/364741.

17. Elikov AV. Oxidative balance in rats during adaptation to swimming load. Bull Exp Biol Med 2016; 162: 180-183, doi: 10.1007/s10517-016-3570-4.

18. Mosmann T. Rapid colorimetric assay for cellular growth and survival: application to proliferation and cytotoxicity assays. J Immunol Methods 1983; 65: 55-63, doi: 10.1016/00221759(83)90303-4.

19. Perez-Severiano F, Rodriguez-Perez M, Pedraza-Chaverri J, Maldonado PD, Medina-Campos ON, Ortiz-Plata A, et al. S-Allylcysteine, a garlic-derived antioxidant, ameliorates quinolinic acid-induced neurotoxicity and oxidative damage in rats. Neurochem Int 2004; 45: 1175-1183, doi: 10.1016/j.neuint.2004.06.008.

20. Ellman GL. Tissue sulfhydryl groups. Arch Biochem Biophys 1959; 82: 70-77, doi: 10.1016/0003-9861(59)90090-6.

21. Ellman GL, Courtney KD, Andres V Jr, Feather-Stone RM. A new and rapid colorimetric determination of acetylcholinesterase activity. Biochem Pharmacol 1961; 7: 88-95, doi: 10.1016/0006-2952(61)90145-9.

22. Bradford MM. A rapid and sensitive method for the quantitation of microgram quantities of protein utilizing the principle of protein-dye binding. Anal Biochem 1976; 72: 248-254, doi: 10.1016/0003-2697(76)90527-3. 
23. Sullivan GM, Feinn R. Using effect size-or why the $p$ value is not enough. J Grad Med Educ 2012; 4: 279-282, doi: 10.4300/JGME-D-12-00156.1.

24. Cochrane DJ. Alternating hot and cold water immersion for athlete recovery: a review. Phys Ther Sport 2004; 5: 26-32, doi: 10.1016/j.ptsp.2003.10.002.

25. Lee H, Natsui H, Akimoto T, Yanagi K, Ohshima N, Kono I. Effects of cryotherapy after contusion using real-time intravital microscopy. Med Sci Sports Exerc 2005; 37: 1093-1098, doi: 10.1249/01.mss.0000169611.21671.2e.

26. Merrick MA, Jutte LS, Smith ME. Cold modalities with different thermodynamic properties produce different surface and intramuscular temperatures. J Athl Train 2003; 38: 28-33.

27. King MA, Clanton TL, Laitano O. Hyperthermia, dehydration, and osmotic stress: unconventional sources of exerciseinduced reactive oxygen species. Am J Physiol Regul Integr Comp Physiol 2016; 310: R105-R114, doi: 10.1152/ajpregu. 00395.2015.

28. Vollaard NB, Shearman JP, Cooper CE. Exercise-induced oxidative stress: myths, realities and physiological relevance. Sports Med 2005; 35: 1045-1062, doi: 10.2165/00007256200535120-00004.

29. Borovikova LV, Ivanova S, Nardi D, Zhang $M$, Yang $H$, Ombrellino $\mathrm{M}$, et al. Role of vagus nerve signaling in CNI1493-mediated suppression of acute inflammation. Auton Neurosci 2000; 85: 141-147, doi: 10.1016/S1566-0702(00) 00233-2.

30. Tagliari B, Tagliari AP, Schmitz F, da Cunha AA, Dalmaz C, Wyse AT. Chronic variable stress alters inflammatory and cholinergic parameters in hippocampus of rats. Neurochem Res 2011; 36: 487-493, doi: 10.1007/s11064-010-0367-0.

31. Klichkhanov NK, Meilanov IS. Effect of hypothermia on kinetic characteristics of acetylcholine esterase in rat erythrocyte membranes. Bull Exp Biol Med 2004; 138: 47-49, doi: 10.1007/BF02694472.

32. Edwards JA, Brimijoin S. Thermal inactivation of the molecular forms of acetylcholinesterase and butyrylcholinesterase. Biochim Biophys Acta 1983; 742: 509-516, doi: 10.1016/ 0167-4838(83)90268-6.

33. Singh DP, Barani Lonbani Z, Woodruff MA, Parker TJ, Steck $R$, Peake JM. Effects of topical icing on inflammation, angiogenesis, revascularization, and myofiber regeneration in skeletal muscle following contusion injury. Front Physiol 2017; 8: 93, doi: 10.3389/fphys.2017.00093.

34. Wilcock IM, Cronin JB, Hing WA. Water immersion: does it enhance recovery from exercise? Int J Sports Physiol Perform 2006; 1: 195-206, doi: 10.1123/ijspp.1.3.195.

35. Borghi SM, Zarpelon AC, Pinho-Ribeiro FA, Cardoso RD, Martins-Pinge MC, Tatakihara RI, et al. Role of TNF-alpha/ TNFR1 in intense acute swimming-induced delayed onset muscle soreness in mice. Physiol Behav 2014; 128: 277287, doi: 10.1016/j.physbeh.2014.01.023.

36. Echtay KS. Mitochondrial uncoupling proteins-what is their physiological role? Free Radic Biol Med 2007; 43: 1351-1371, doi: 10.1016/j.freeradbiomed.2007.08.011

37. Bernas T, Dobrucki J. Mitochondrial and non-mitochondrial reduction of MTT: interaction of MTT with TMRE, JC-1, and NAO mitochondrial fluorescent probes. Cytometry 2002; 47 : 236-242, doi: 10.1002/cyto.10080. 